\title{
Diversity in Family Structure-Diversity in Communication between Family Members?
}

\author{
Piia M. Björn ${ }^{1 *}$, Minna Kyttälä ${ }^{2}$ \\ ${ }^{1}$ Department of Education/Special Education, University of Jyväskylä, Jyväskylä, Finland \\ ${ }^{2}$ University of Turku, Turku, Finland \\ Email: "piia.bjorn@jyu.fi
}

Received November $17^{\text {th }}, 2012$; revised December $18^{\text {th }}, 2012$; accepted January $16^{\text {th }}, 2013$

\begin{abstract}
This study aims at investigating the parent-adolescent communication of Finnish families from a multiinformant perspective. Thirteen- and fourteen-year-old adolescents $(n=171)$ and their parents were asked to complete a questionnaire examining positive and problematic communication between the two parties. Information about their family structure was collected. The results indicated an interrelationship between parental and adolescent assessments, particularly regarding negative aspects of communication. The boys assessed their communication with parents as more positive than did the girls. The results showed that the mothers still are the synchronizing hearts of communication in modern families, whereas the fathers' roles in family communication were more modest suggesting that the stereotypical roles in Finnish families persist even today.
\end{abstract}

Keywords: Parent-Adolescent Communication; Positivecommunication; Problems in Communication; Family Structure

\section{Introduction}

The children enter the school system from a variety of different kinds of families every day. Thus, the present study adds to existing literature by looking into the communicative atmospheres in contemporary families: Are the communicative roles the same they used to be or has there been some kind of change as the family structures certainly have changed? Nuclear family with two married parents and their children used to be the expected family structure in Finland and elsewhere. However, as divorce rates are quite high and diversity in family structure (one-parent families, families with parents of the same sex, parents with new spouses and children from earlier marriages) is becoming customary (Jallinoja \& Widmer, 2011), it might be expected that the communication patterns in families between its' members also show discrepancy (White, 1996). Faber and others (2003) have suggested that well-functioning communication between parents and children includes the emotional security needed to express negative issues without fear of embarrassment, for example (see also Campione-Barr \& Smetana, 2004; De Los Reyes, 2010; Kim et al., 2001; Smetana et al., 2006). It has alsobeen suggested that the possibility to freely and reciprocally express opinions and thoughts (Smith \& Kerpelman, 2002), along with a mutual willingness to address problematic episodes at the time of disagreement (Perosa \& Perosa, 1993; Perosa, Perosa, \& Tam, 1996), are present in open parent-adolescent communication.

Adolescent, maternal, and paternal views of their communicative interactions with each other have been found to differ to some extent, regardless of the family structure (Callan \& Noller, 1986). Overall, adolescents have been shown to view their interaction with family members in a more negative light than their parents do (Callan \& Noller, 1986; Epstein \& Ward, 2011;

*Corresponding author.
Xiao et al., 2011). Teenagers have been said to more often experience openness in communication with their mothers than with their fathers (Noller \& Bagi, 1985; White, 1996). Moreover, family members have been usually found to interact in accordance with more or less stereotypical role-taking traditions (Noller \& Callan, 1988).

There also is evidence on gender-based differences in how positive or negative the family communication is assessed to be. Mothers are usually considered as having more open interrelationship with their children in comparison to fathers. For example, Olson and others (1983) observed that mothers often considered themselves as having more satisfying interactions with their adolescent children than fathers did. Also recently, Rosnati, Iafrate and Scabini (2011) reported that mothers experienced a more open communication with their children than did fathers in diverse family groups (foster, inter-country adoptive and biological Italian families).

\section{The Current Study}

The modern family systems are in constant change in the sense of multiple structures. This change might reflect on the way family members evaluate their communication. Thus, the present study seeks to investigate, whether the modern (Finnish) families still confirm the traditional roles assuming that 1) the mothers are the central communicators in the family; 2) the fathers do not have such a strong role in the communication; and 3) there might also be gender differences between the adolescent participants of the family primarily due to their differing developmental phases. The girls might be expected to report less openness in their family communication due to their earlier entrance into puberty (see also Olson et al., 1983).

The triadic association between parent-adolescent communication as assessed by the adolescents and their mothers and 
fathers was the core of the analysis. Furthermore, the adolescent's gender and family structure were taken into account.

\section{Method}

\section{Participants}

Adolescents. The present study is part of the MASA research project (Mathematical learning difficulties and Sociocultural factors among Finnish Adolescents; see Kyttälä \& Björn, 2010; Björn \& Kyttälä, 2011). Data were collected from two cities in Central and Southern Finland. The main sample comprised 171 eighth-graders (94 male and 77 female), born in 1993 (aged 13 or 14 years). The sample was homogeneous in terms of ethnic and cultural background, and all the children spoke Finnish as their native language.

\section{Procedure}

The adolescents were asked to fill in the Barnes and Olson (1982) questionnaire about parent-adolescent communication. All of the questionnaires were returned, as they were asked to fill in the questionnaire during a normal school day. Background information about their individual educational levels, as well as family structure, was gathered from the parents along with the Parent-Adolescent Communication Questionnaire. 128 questionnaires for the parents were first sent to homes by the children's schools. 43 families did not participate this part of the study. Return percentage was $41 \%$. Parental assessments of their parent-adolescent communication were available from 83 mothers and 71 fathers. Moreover, both the mother and father filled in the questionnaire in 65 families (60 co-habiting parents) in the study. There were 23 cases -18 mothers and 5 fathersin which only one parent completed the questionnaire. A total of 60 families were composed of two parents (either married or engaged) and their own children; eight families consisted of the mother or the father living with a new spouse and their children; and 20 families had a single parent (mother or father). The family structure variable was then dichotomyzed for further analysis $(2=$ two-parent intact family, $1=$ other; see also Turner et al., 2004). The sample was representative compared to the distribution among the structure of Finnish families (Finnish statistical centre, 2011).

\section{The Questionnaire}

Parent-Adolescent Communication Questionnaire. The views of parents and adolescents on their communication were assessed using 25-point Likert scale items, adapted to Finnish from Barnes and Olson's Parent-Adolescent Communication Scale (1982). The scale measures communication between teenagers and their parents. The questionnaire contains two subscales: one subscale-comprising items 1, 3, 6, 7, 8, 9, 13, 14, 16, and 17-measures Positive aspects of communication (e.g., "I can discuss my beliefs with my child/parent without feeling restrained or embarrassed"); and the other-items 2, 4, 5, 10, $11,12,15,18,19$, and 20 -measures problems in communication (e.g., "Sometimes I have trouble believing everything my child/parent tells me"). Response choices ranged from $1=$ "I strongly disagree" to 5 = "I strongly agree". The scoring was reversed for the Negative aspects of the communication subscale, in which high scores indicate low negativity in communication.

The Cronbach's alpha reliabilities were notated such that the first figure in parentheses indicates the mothers' scales, the second the fathers' scales and the third the adolescents' scales. They were $(.77, .78$, and .84$)$ for the total scale; $(.69, .59$, and .68) for the problems in communication; and $(.70, .74$, and .86) for the Positive aspects of communication. According to Sabatelli, Anderson and LaMotte (2005), the alpha coefficients have been found to be in the .78 to .92 range in both subscales as well as the total scale. Means and standard deviations of the main variables by family structure are presented in Table 1.

\section{Analysis Strategy}

The statistical analyses were carried out in the following steps. First, covariance models were calculated including adolescent, maternal, and paternal assessments of Parent-Adolescent Communication separately for girls and boys to investigate whether the assessments on family communication are in accordance between its members and also, to see whether the models are different for girls and boys. For this the total sum scores was used for both Problems in communication (scoring reversed) and Positive aspects of communication subscales.

Table 1.

Means (M), Standard Deviations (SD), t-tests and Intra-Class Correlations between Family Structure and assessments on Parent-Adolescent Communication.

\begin{tabular}{|c|c|c|c|c|}
\hline Variable & Biological two-parent family & Other & & Family Structure \\
\hline & $\mathrm{M}(\mathrm{SD})$ & $\mathrm{M}(\mathrm{SD})$ & t-value & Intra-Class Correlation \\
\hline Pos. Communication/Girls & $35.92(8.97)$ & $34.21(7.73)$ & .67 & .21 \\
\hline Pos. Communication/Boys & $37.32(5.91)$ & $36.54(7.67)$ & .18 & .21 \\
\hline Probl. Communication/Girls ${ }^{1}$ & $33.48(4.63)$ & $30.32(5.58)$ & $2.10^{*}$ & .44 \\
\hline Probl. Communication/Boys ${ }^{1}$ & $34.76(6.00)$ & $33.68(5.46)$ & .59 & .07 \\
\hline Pos. Communication/Mothers & $40.21(5.01)$ & $41.07(4.03)$ & .80 & .00 \\
\hline Probl. Communication/Mothers ${ }^{1}$ & $40.96(4.67)$ & $38.07(5.65)$ & $2.51^{* *}$ & .12 \\
\hline Pos. Communication/Fathers & $38.67(4.53)$ & $38.25(5.67)$ & .33 & .03 \\
\hline Probl. Communication/Fathers ${ }^{1}$ & $38.78(4.56)$ & $38.40(5.19)$ & .30 & .03 \\
\hline
\end{tabular}

Note. 1 = Scoring reversed: higher the scores the less negativity in communication. ${ }^{*} p=<0.05,{ }^{* *} p=<0.01,{ }^{* * *} p<0.001$. Family Structure was dichotomised as $1=$ Other than biological two-parent family; 2 = Biological two-parent family. 
Hence, a low total sum score along the Problems in communication subscale represented quite negative family communication, whereas a high total sum score represented more positive family communication.Second, intra-class correlations were calculated to investigate the extent to which family structureaccounts for the adolescent and parental assessments of the Positive aspects and Problems - the two separate subscales - in their communication. For this, the family structure variable was dichotomized, with the two-biological-parent family being considered one group and all the other family types being considered the other group. As completing analyses independent samples t-tests were applied. The covariance analyses were carried out with the AMOS statistical package (version 19.0; Arbuckle, 2011). Goodness-of-fit was evaluated using $\chi^{2} / \mathrm{df}$. This particular index is sufficient when using simple covariance modeling. Other analyses were done using IBM Statistical Package SPSS version 19.0 (Arbuckle, 2011). To calculate the intra-class correlations a formula of $[\rho=$ variance component estimate/(variance component estimate + variance component error)] was applied. Intra-class correlations give information about the proportion (transferable into percentages by multiplying the correlation coefficient with 100) which a certain variable's variance (usually categorical variable) accounts for another variable's (usually continuous variable) variance.

\section{Results}

To examine whether the assessments of parent-adolescent communication between adolescents and their mothers and fathers were interrelated, analyses of covariance was calculated. In Figure 1, schematic representation of the models is shown. First, the girls' model (Figure 2) for Positive family communication was calculated. The model was just-identified suggesting that there was no need to use fit-indexes. Inspection of the covariances showed an interrelation only between maternal and

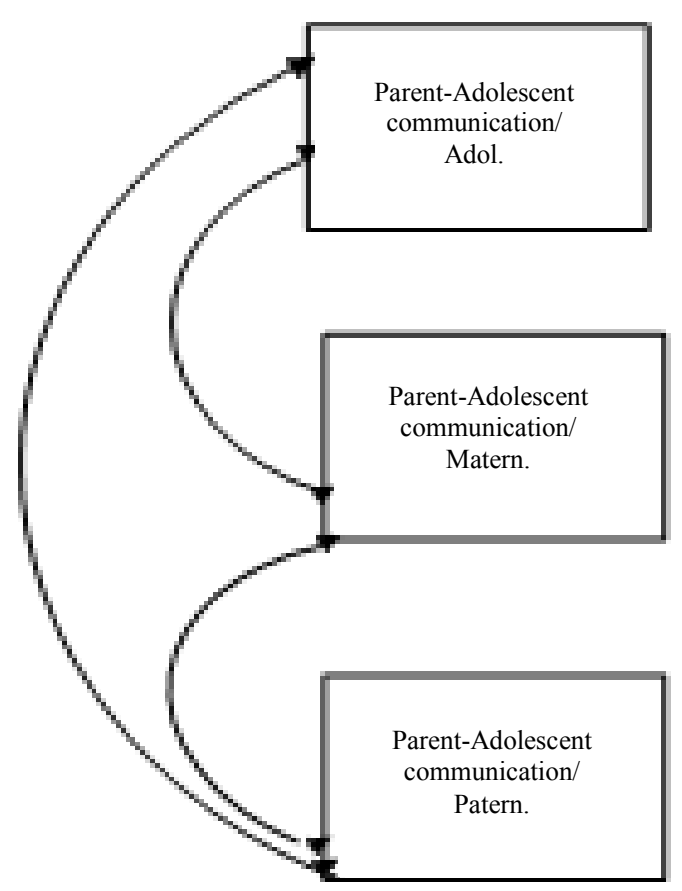

Figure 1.

Schematic representation of the covariance models.

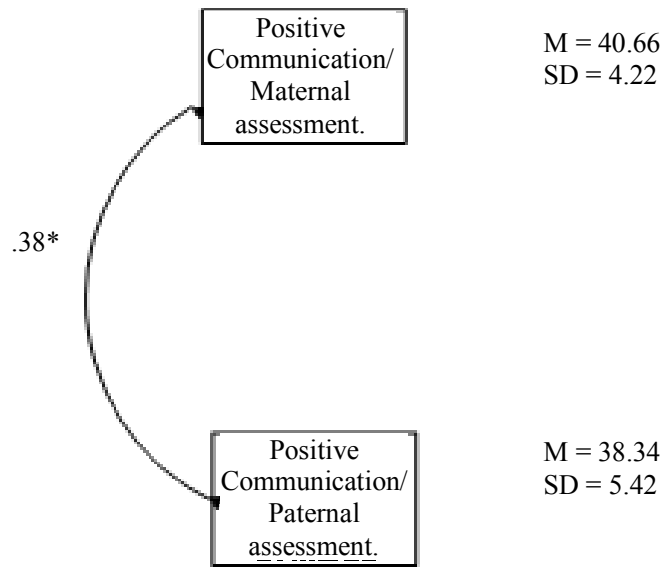

Figure 2.

Significant interrelationships in the girls' model for positive communication.

paternal $(\mathrm{Cov}=0.38, p<.05)$ assessments. Thus, there was no statistically significant interrelation between the assessments by the girls and the parents. However, the girls' model (Figure 3) for Negative aspects of family communication included the whole triad: the assessments between girls, mothers and fathers were interrelated, suggesting that there was a common view on possible problems - or lack of them-between girls and their parents.

The boys' model (Figure 4) regarding Positive family communication [model just-identified] included statistically significant covariation between the boys' and maternal assessments $(\mathrm{Cov}=0.46, p<.05)$. The boys' model $\left[\chi^{2}(1)=.815, p=.37\right]$ regarding Negative aspects of communication (Figure 5) was very similar to the girls' model, but with one exception: the paternal assessments were not associated with the maternal assessments.

These results suggested that, in particular, the assessments of Negative aspects of parent-adolescent communication by adolescents and mothers and by mothers and fathers covariatedthat is, shared a common change to a statistically significant extent. These results further showed that while a relatively common view was held by all family members concerning the problems in family communication, their views on positive family communication were not so unified. Also, the girls' and boys' assessments of family communication were different.

On average, mothers reported the fewest problems in communication with adolescents $(M=39.92)$ and also the most positive communication $(\mathrm{M}=40.51)$ in general. The adolescents reported the most problems in communication $(\mathrm{M}=33.02)$ and the least positive communication with their parents $(\mathrm{M}=$ 35.11). However, the differences between means were not statistically significant. Furthermore, an additional t-test suggested that the boys' assessments of items along the Problems in communication subscale in particular differed from the girls' assessment to a statistically significant degree $[\mathrm{t}=.614, p$ $<.05]$, suggesting that the girls $(\mathrm{M}=31.92, \mathrm{SD}=5.22)$ viewed their communication with their preferred parent as being more negative than did the boys $(\mathrm{M}=33.92, \mathrm{SD}=6.71)$.

Next, the extent to which family structure (two-biologicalparent intact family vs. other) contributes to assessments of parent-adolescent communication was examined. The intraclass correlations are presented in Table 1. The results showed 


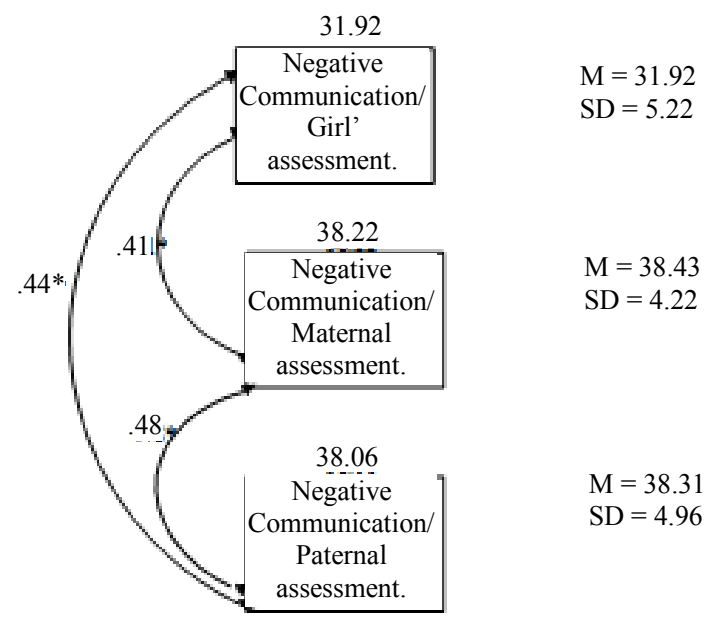

Figure 3.

Significant interrelationships in the girls' model for negative communication.

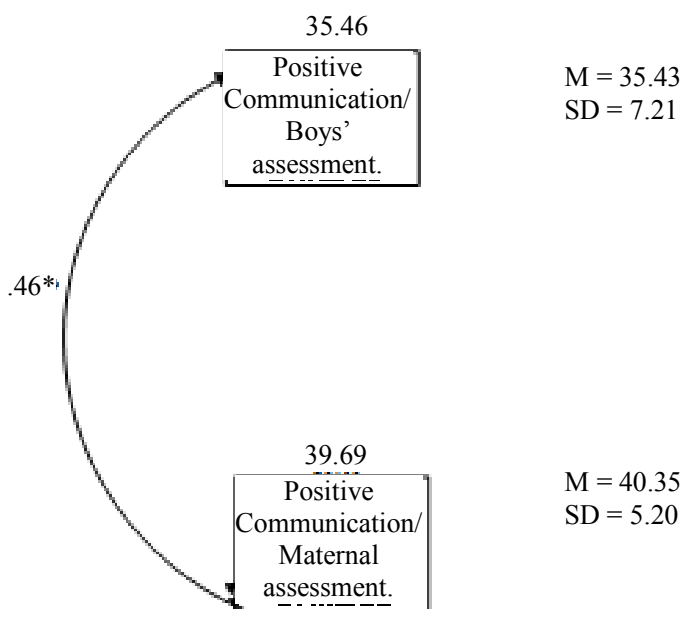

Figure 4.

Significant interrelationships in the boys' model for positive communication.

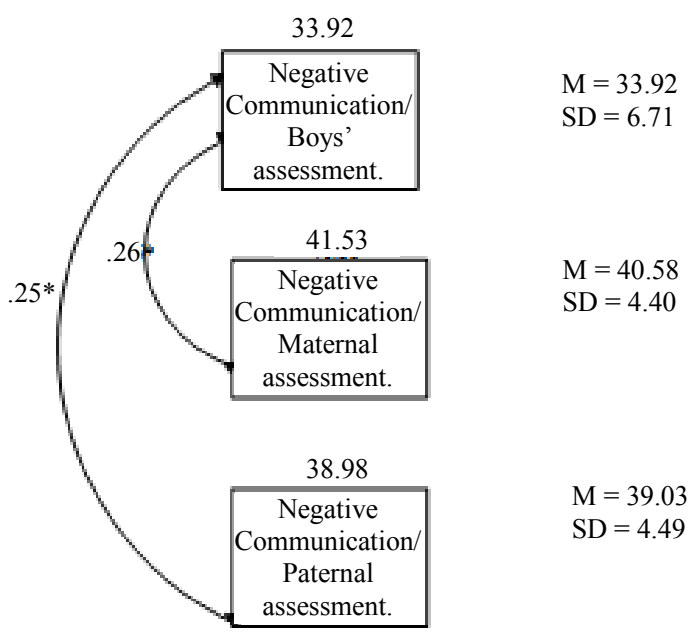

Figure 5.

Significant interrelationships in the boys' model for negative communication. that family structure accounted for the girls' and boys' assessments of parent-adolescent communication ( $\rho$ :s ranged from .21 to .44), suggesting that adolescents from families with a twobiological-parent intact structure had evaluated their communication as being more positive, according to this data, than did those with other types of families. T-tests confirmed that particularly the girls coming from two-parent intact families viewed their communication as being statistically significantly more positive $[\mathrm{t}=2.10, p<.05]$. For girls, the family structure accounted for $44 \%$ of the variation in the assessments of Positive communication. In general, all the adolescent assessments of family communication were at least mean-wise more positive among adolescents coming from two-parent intact families.

The intra-class correlations for parents were very small: they ranged from only 0.00 to 0.12 . The mothers in nuclear-family structures reported their family communication as being statistically significantly less Negative: $[\mathrm{t}=2.51, p<.01]$, whereas the mothers from other types of families reported slightly more Positive aspects of communication in their families $(\mathrm{M}=$ 41.07 vs. $\mathrm{M}=40.21$ ).

\section{Discussion}

The aim of this study was to investigate the triadic interrelations between positive and negative aspects of Finnish parent-adolescent communication from the perspectives of parents and adolescents. The results revealed that especially adolescent, maternal and paternal assessments of negative aspects of communication shared a common change-suggesting that family members are mutually aware of whether or not there are problems in trust and communication within the family. This finding is in line with the results reported by White (1996), as well as Xiao and others (2011). Further, a common finding has been that family members communication patterns are quite complex and, above all, the quality of communication between family members may be interpreted differently in different time points at least to some extent (see, De Los Reyes et al., 2010). In the present study, the girls' and boys' assessments on family communication differed to some extent. In all of the models the mothers' assessments on communication was interrelated with the assessments of other family members, whereas the paternal assessments were not interrelated with the others' assessments in the same way. This result might be due to the previous results according to which the teenagers have been said to more often experience openness in communication with their mothers than with their fathers (Noller \& Bagi, 1985; White, 1996). Gender certainly appears to play a multi-faceted and intriguing role in parent-adolescent communication. For example, Heller and others (2006) found an adolescent's gender to be a statistically significant predictor of adolescent-assessed openness in both mother- and father-adolescent communication, whereas Hauser et al. (1987) found, among other factors, that the parent's gender explained perceived differences in the interactions with the adolescent offspring. A study by Kawaguchi and others (1998), which showed parent and particularly mother temperament to account for the gender differences in parent-adolescent communication and adolescent-parent relationships. Further, the mothers have been the communicative par- ties in the families over the decades in light of the members' stereotypical roles (Noller \& Bagi, 1985, Noller \& Callan, 1988) and thus, more openness was expected from their assessments. In contrast, the girls might be expected to report less positivity in 
their family communication due to their earlier entrance into puberty (see also Olson et al., 1983). Especially mothers and adolescents shared an understanding of their communication problems (see also Smith \& Kerpelman, 2002). The results also suggested, that in contrast to fathers, mothers evaluated communication with their adolescent children as being very positive (see also Campione-Barr \& Smetana, 2004; Olson et al., 1983; Schwartz, Barton-Henry, \& Pruzinsky, 1985). In turn, as was posited, the highest amount of Negative communication in general and the lowest amount of Positive communication with their parents was reported by the adolescents (see also Noller \& Bagi, 1985). In addition, the girls reported more negativity in their parent-adolescent communication than did the boys. The mothers' presence in all of the models tells something about modern families: the mothers remain at the communicative core of the families. In other words, although the fathers are present in family activities much more than they used to be, the maternal role as a communicative bridge between family members has sustained.

Secondly, the extent to which family structure is related to adolescent, maternal and paternal views on communication was examined. As expected, the results showed that family structure accounted for adolescent assessment of parent-adolescent communication in particular: adolescents and notably girls from families with two-parent intact structure had evaluated their communication as more positive according to this data than did those adolescents with other types of families. This result suggests that belonging to a family with two parents is a privilege in the sense of expecting more open family communication (Smith \& Kerpelman, 2002; Perosa \& Tam, 2006). The stability of family structure has been observed to be related to perceived maternal and paternal support in earlier studies, as well. For example, Turner et al. (2004) found that children with twoparent intact families perceived more maternal and paternal support than the children from single-parent families. Family structures other than two-parent families have often been observed to be related to issues such as fewer economic resources or behavior problems in adolescence (Perosa \& Perosa, 1993; Perosa et al., 1996). Feedback the individuals get from one's actions (LaRossa \& Reitzes, 1993) either helps or constrains a family member in finding his or her place within a family system. This might give an explanation to the question why the modern families still seek to communicate according to very traditional roles: it might be the only way to search for some kind of stability between its members (Epstein \& Ward, 2011).

\section{Conclusion}

Overall, the results of the present study revealed that the modern families in Finland still communicate according to very traditional roles.Moreover, this finding appears to be in line with recent findings across a variety of cultures (see, Rosnati et al., 2011; Xiao et al., 2011) and in a variety of research settings. Further, there was an agreement on family communication between the adolescent and adult members regarding problems in communication in the current data. The communication was interpreted as being more positive in nuclear families than in other types of families. This suggests that stability in family structure yields positive communication outcomes in adolescence. However, the result does not indicate that diverse families in the sense of their structures would not be able to manage positive communication between its members. Instead, with enough time, also families in change can create their own traditions and ways to communicate.

\section{REFERENCES}

Arbuckle, J. L. (2010). Amos 18.0 user's guide. Chicago, IL: SPSS Inc. Barnes, H. L., \& Olson, D. L. (1982). Parent-adolescent communication scale. In D. H. Olson et al. (Eds.), Family inventories: Inventories used in a national survey of families across the family life cycle (pp. 33-48). St Paul: Family Social Science, University of Minnesota.

Barnes, H. L., \& Olson, D. L. (1985). Parent-adolescent communication and the circumplex model. Child Development, 56, 438-447.

Björn, P. M., \& Kyttälä, M. (2011). Family structure and academic skills among Finnish adolescents. European Journal of Psychology of Education, 26, 465-477. doi:10.1007/s10212-011-0058-5

Callan, V. J., \& Noller, P. (1986). Perceptions of communicative relationships in families with adolescents. Journal of Marriage and the Family, 48, 813-820. doi:10.2307/352574

Campione-Barr, N., \& Smetana, J. G. (2004). In the eye of the beholder: Subjective and observer ratings of middle-class African-American mother-adolescent interactions. Developmental Psychology, 40, 927947. doi:10.1037/0012-1649.40.6.927

De Los Reyes, A., Goodman, K. L., Kliewer, W., \& Reid-Qiñ Ones, K. R. (2010). The longitudinal concistency of mother-child reporting discrepancies of parental monitoring and their ability to predict child delinquent behavior two years later. Journal of Youth and Adolescence, 39, 1417-1430. doi:10.1007/s10964-009-9496-7

Epstein, M., \& Ward, L. (2011). Exploring parent-adolescent communication about gender: Results from adolescent and emerging adult samples. Sex Roles, 65, 108-118. doi:10.1007/s11199-011-9975-7

Faber, A. J., Edwards, A. E., Bauer, K. S., \& Wetchler, J. L. (2003). Family structure: Its effects on adolescent attachment and identity formation. The American Journal of Family Therapy, 31, 243-255. doi:10.1080/01926180390201945

Finnish statistical centre (2011).

http://tilastokeskus.fi/til/perh/2010/perh_2010_2011-0527_tie_001_fi .html

Hauser, S. T., Book, B. K., Houlihan, J., Powers, S., Weiss-Perry, B., Follansbee, \& Noam, G. G. (1987). Sex differences within the family: Studies of adolescent and parent-family interactions. Journal of Youth and Adolescence, 3, 199-220. doi:10.1007/BF02139091

Heller, S. R., Robinson, L. C., Henry, C. S., \& Plunkett, S. W. (2006). Gender differences in adolescent perceptions of parent-adolescent openness in communication and adolescent empathy. Marriage \& Family Review, 40, 103-122. doi:10.1300/J002v40n04 06

Jallinoja, R., \& Widmer, E. D. (2011). Families and kinship in contemporary Europe: Rules and practices of relatedness. Basingstoke: Palgrave Macmillan. doi:10.1057/9780230307452

Kim, K. J., Conger, R. D., Lorenz, F. O., \& Elder Jr., G. (2001). Parentadolescent reciprocity in negative affect and its relation to early adult social development. Developmental Psychology, 37, 775-790. doi:10.1037/0012-1649.37.6.775

Kyttälä, M., \& Björn, P. M. (2010). Prior mathematics achievement, cognitive appraisals and anxiety as predictors of Finnish students' later mathematics performance and career orientation. Educational Psychology, 4, 431-448. doi:10.1080/01443411003724491

LaRossa, R., \& Reitzes, D. C. (1993). Symbolic interactionism and family studies. In P. G. Doherty, W. J. LaRossa, R. Schumm., \& S. K. Steinmetz (Eds.), Sourcebook of family theories and methods. New York: Plenum Press, 135-163. doi:10.1007/978-0-387-85764-0 6

Noller, P., \& Bagi, S. (1985). Parent-adolescent communication. Journal of Adolescence, 8, 125-144. doi:10.1016/S0140-1971(85)80042-7

Noller, P., \& Callan, V. (1988). Understanding parent-adolescent interactions: Perceptions of family members and outsiders. Developmental Psychology, 24, 707-714. doi:10.1037/0012-1649.24.5.707

Olson, D. H., McCubbin, H. I., Barnes, H. L., Larsen, A. S., Muxen, M. J., \& Wilson, M. A. (1983). Families: What makes them work. Beverly Hills, CA: Sage. 


\section{P. M. BJÖRN, M. KYTTÄLÄ}

Perosa, S. L., \& Perosa, L. M. (1993). Relationships among Minuchin's structural family model, identity achievement, and coping style. Journal of Counseling Psychology, 40, 479-489.

doi:10.1037/0022-0167.40.4.479

Perosa, L. M., Perosa, S. L., \& Tam, H. P. (1996). The contribution of family structure and differentiation to identity development in females. Journal of Youth and Adolescence, 25, 817-837. doi:10.1007/BF01537456

Rosnati, R., Iafrate, R., \& Scabini, E. (2011). Parent-adolescent communication in foster, inter-country adoptive, and biological Italian families: Gender and generational differences. International Journal of Psychology, 42, 36-45. doi:10.1080/00207590500412128

Sabatelli, R. M., Anderson, S. A., \& LaMotte, V. A. (2005). Assessing outcomes in child and youth programs: A practical handbook. University of Connecticut and State of Connecticut.

Smetana, J. G., Metzger, A., Gettman, D. C., \& Campione-Barr, N. (2006). Disclosure and secrecy in adolescent-parent relationships.
Child Development, 77, 201-217. doi:10.1111/j.1467-8624.2006.00865.x

Smith, S., \& Kerpelman, J. L. (2002). Adjudicated adolescent girls and their mothers: Examining relationship quality and communication styles. Journal of Addictions \& Offender Counseling, 23, 15-29. doi:10.1002/j.2161-1874.2002.tb00167.x

Turner, S. L., Steward, J. C., \& Lapan, R. T. (2004). Family factors associated with sixth-grade adolescents' math and science career interests. The Career Development Quarterly, 53, 41-53. doi:10.1002/i.2161-0045.2004.tb00654.x

White, F. A. (1996). Parent-adolescent communication and adolescent decision-making. Journal of Family Studies, 1, 41-56. doi: $10.5172 /$ jfs.2.1.41

Xiao, Z., Xiaoming, L., \& Stanton, B. (2011). Perceptions of parentadolescent communication: It is a matter of perspective. Psychology, Health \& Medicine, 16, 56-65. doi:10.1080/13548506.2010.521563 